\title{
IMPACT OF COVID-19 PANDEMIC ON FETUS AND NEWBORN: \\ A SYSTEMATIC REVIEW
}

\author{
Ika Yulianti, Rahmi Padlilah, Agus Purnamasari
}

Midwifery Program, Faculty of Health Sciences, Universitas Borneo Tarakan, North Kalimantan

\begin{abstract}
Background: The COVID-19 pandemic has reported the potential infection to children, including newborns. The data for the intrauterine transmission of Covid-19 during pregnancy and its impact is still limited. This study aimed to investigate the impact of Covid-19 pandemic on fetus and newborns.

Subjects and Method: A systematic review was conducted by searching from PubMed, Google Scholar, JAMA, and ScienceDirect conducted in April 2020. The keywords were "child health" AND "COVID-19" OR "newborn" AND "novel coronavirus" AND "infection" OR "intrauterine transmission AND COVID- 19 AND Review". The data were reported systematically.

Results: The reviewed articles were cohort retrospective, case report, review, and systematic review. Intrauterine transmission of Covid-19 in pregnancy remained uncertain. Some studies reported the confirmation of infected Covid-19 in newborns within $<2$ hours to 2 days birth. Supportive therapy was given according to the clinical conditions of newborns.

Conclusion: There is a lack of evidence in the intrauterine transmission of Covid-19 in pregnancy. The infected newborns with Covid-19 are confirmed within $<2$ hours to 2 days. Supportive therapy is conducted according to the clinical conditions of newborns.
\end{abstract}

Keywords: newborns, Covid-19, infection

Correspondence:

Ika Yulianti. Midwifery Program, Faculty of Health Sciences, Universitas Borneo Tarakan. Jl. Amal Lama No. 1 East Tarakan, North Kalimantan. Email: ikatamaevan@gmail.com. Mobile : +628115440036 .

The $7^{\text {th }}$ International Conference on Public Health

Solo, Indonesia, November 18-19, 2020 | 248 https://doi.org/10.26911/the7thicph.03.68 